\title{
Obesity Peptide: Prokineticin
}

\author{
Canan Nebigil
}

Additional information is available at the end of the chapter

http://dx.doi.org/10.5772/65701

\begin{abstract}
Obesity confers an increased risk for cardiovascular renal diseases, diabetes mellitus, nonalcoholic steatohepatitis, musculoskeletal disorders, and cancers. Prokineticin-2 is a peptide hormone, which exists as both a circulating hormone system and a local paracrine-signaling mechanism within various tissues including the brain, kidney, and adipose. It acts on the G-protein-coupled receptors (GPCRs) PKR1 and PKR2. The role of prokineticin-2 in the central nervous system is the control of food intake. Its anorexigenic effect is at least partly through the hypothalamic melanocortin system. Prokineticin-2 also prevents adipose tissue expansion by limiting preadipocyte proliferation and differentiation capacity. Prokineticin-2 signaling is important for insulin capillary passages. It also regulates heart and kidney development and function. Here, we discuss a new obesity peptide prokineticin signaling in central regulation of food intake, adipocyte tissue development, and cardiovascular function. Prokineticin may play a key role in the association between obesity and cardiovascular diseases. We also outline the potential of prokineticin receptor- 1 as target for the treatment of obesity and cardiovascular diseases.
\end{abstract}

Keywords: prokineticin, GPCRs, obesity, diabetes, anorexigenic, angiogenic

\section{Introduction}

Obesity is a major health problem and an increased risk factor that worsens cardiovascular events leading to higher morbidity and mortality. [1] Several cardiovascular diseases can also occur due to structural and functional changes of the myocardium through excess fat deposition and other mechanisms related to obesity [2]. However, the mechanisms of relation between obesity and cardiovascular events are unclear. Nevertheless, pharmacological therapy for obesity has great potential to improve cardiovascular problems. Several anorexcigenic peptides 
have been studied as potential drugs in the treatment of obesity [3]. Recent evidence showed that some brain regions may not only be involved in food intake regulation but also play an important role in the regulation of cardiovascular blood homeostasis [4]. The rising prevalence of both obesity and heart failure make this association an important target for prevention. Therefore, it is important to determine the common mechanisms regulating both obesity and cardiovascular events. Identification of signaling pathways linking obesity and cardiovascular disease is important for the development of novel therapeutics. Here, we summarize the current information on the role of anorexigenic peptide prokineticin in obesity and cardiovascular renal diseases, emphasizing prokineticin receptor-1 signaling in these events.

\section{Prokineticins and their receptors}

Prokineticins are anorexigenic and angiogenic hormones. Because of the structural, signaling and functional similarities, prokineticins are considered as cytokines/chemokines [5]. They are released principally by macrophages and reproductive organs [6]. Recently, prokineticin is considered as an adipokine because a high level of prokineticins has been found in obese human WAT [7]. These small peptides (80-120 amino acids) are called prokineticins, because these molecules were first identified as potent contractile factors in the gastrointestinal tract [8]. Two isoforms of prokineticins have been identified: prokineticin-1 and prokineticin- 2 . Prokineticin-1 has been originally called as endocrine gland-derived vascular endothelial growth factor (EG-VEGF), [9] because of its functional similarity to VEGF. Prokineticin-2 is also called as Bv8. Both of these peptides are $45 \%$ identical with highly conserved $\mathrm{N}$-terminal AVITGA motif essential for their biological activity $[6,10]$. Prokineticin activity is mediated by two G-protein-coupled receptors, PKR1 and PKR2 [11].

\subsection{Prokineticin-2 is an anorexigenic peptide}

Circulating hormones and nutrients are integrated to mediate the regulation of short-term and long-term dietary intakes in the hypothalamus. A feeding and energy homeostasis control center in the hypothalamus is called as arcuate nucleus (ARC) [12, 13]. The ARC integrates most of the peripheral hormonal signals including leptin, insulin and ghrelin. The ARC has two major subpopulations of primary neurons that express neurohormones with opposing effects on food intake. ARC neurons that release the proopiomelanocortin (POMC)-derived peptide alpha-melanocyte-stimulating hormone $(\alpha-\mathrm{MSH})$ and cocaine- and amphetamineregulated transcript (CART) peptide potently reduce food intake [13, 14]. However, neuropeptide $\mathrm{Y}(\mathrm{NPY})$-producing neurons in the ARC stimulate food intake.

Prokineticin-2 is involved in the control of food intake and of fat mass through actions in the ARC in the hypothalamus [15]. PKR1 receptor is expressed on both NPY/AgRP and POMC/ CART neurons. Intracranial injection of prokineticin-2 in rats strongly decreases food intake. Controversy, anti-prokineticin-2 antibody increases food intake. Anorexigenic effect of prokineticin-2 is mediated at least partly via the hypothalamic ARC melanocortin system. Prokineticin-2 increases the release of alpha-MSH from ex vivo hypothalamic explants. Recently, 
PKR1 has been shown as the first non-melanocortin GPCR to be regulated by the melanocortin receptor accessory protein 2 (MRAP2). Indeed, MRAP2 significantly and specifically inhibits PKR1 signaling [16].

Peripheral administration of prokineticin-2 reduces food intake and body weight in both lean mice and diet-induced obesity models [17]. This effect of prokineticin-2 is not evident when appetite is increased or feeding behavior is promoted. Hypothalamic prokineticin-2 levels were found extremely high in the early neonatal period. However, a decreased level of prokineticin-2 was evident under fasting conditions [18]. Prokineticin-2-knockout mice became obese at the late age. Humans with the inactivating mutations of prokineticin-2 gene are also obese $[17,19]$. The anorectic effects of prokineticin-2 are abolished by PKR1 antagonists and not observed in mice lacking PKR1 [17]. Thus, the anorectic effects of prokineticin2 in the hypothalamus are mediated by PKR1.

\subsection{Prokineticin in the development of obesity}

The mechanisms underlying the development of obesity include the hypertrophy and/or hyperplasia of adipocytes, adipose tissue (AT) inflammation, impaired extracellular matrix remodeling and fibrosis together with an altered secretion of adipokines [20]. AT expansion involves two distinct mechanisms: an enlargement in adipose cells and an increase of adipocytes number [21]. Differentiated adipocytes are post-mitotic and therefore hyperplasia is the result of increased de novo adipocyte formation (adipogenesis). Impaired adipogenesis is associated with insulin resistance [22]. The balance between proliferation and differentiation of preadipocytes and adipocyte apoptosis or necrosis determines adipocyte number.

Prokineticin-2 levels were found to be high in obese human WAT [7]. Prokineticin-2 suppresses AT expansion by two distinct mechanisms: the central regulation of food intake and limiting preadipocyte proliferation and differentiation. The central regulation of body weight is counteracted by loss of PKR1 in adipose tissue in mice. Indeed, an abnormally excessive abdominal fat mass accumulation was observed in these mice where the PKR1 specifically deleted in the adipocytes (PKR1 $1^{\text {ad-l- }}$ ) [7]. The formation of new adipocytes in both PKR1 null and PKR1 $1^{\text {ad-l }}$ mice was resulted from an acceleration of preadipocyte proliferation and differentiation. AT proliferative phenotype has switch to AT hypertrophic phenotype when these mice were treated with a high-fat diet, implicating high calorie intake is involved in the conversion of hyperplasia to hypertrophy. In isolated preadipocytes, PKR1 activation suppresses proliferation and adipogenic differentiation [38].

Both PKR1 ${ }^{\text {null }}$ and PKR1 ${ }^{\text {ad-- }}$ mice display abdominal obesity [7] However, only PKR1 $1^{\text {null }}$ mice have peripheral obesity with a diabetes-like syndrome. Thus, non-adipocyte PKR1-mediated events contribute to the development of a diabetes-like syndrome. Indeed, endothelial-specific PKR1-knockout mice (PKR1 ${ }^{e c-l}$ ) [23] had insulin resistance in adipocytes. In PKR1 $1^{\text {ec-l }}$ adipocytes, insulin cannot promote normal fat storage, resulting in excess circulating free fatty acids that, in turn, further contribute into insulin resistance in muscle, leading to diabetes-like syndrome. However, it seems that PKR1 has no direct effect on fat deposition in adipocytes. PKR1 ${ }^{\text {ad- }- \text { mice }}$ did not have severe accumulation of fat tissue in their adipocytes. Since adipocytes are not created from other adipocytes, but they arise from precursor cells (preadi- 
pocytes), PKR1 suppress the ability of these precursor cells to become adipocytes (Figure 1) [7]. The expansion and metabolism of the adipose tissue are the major problem in obesity.

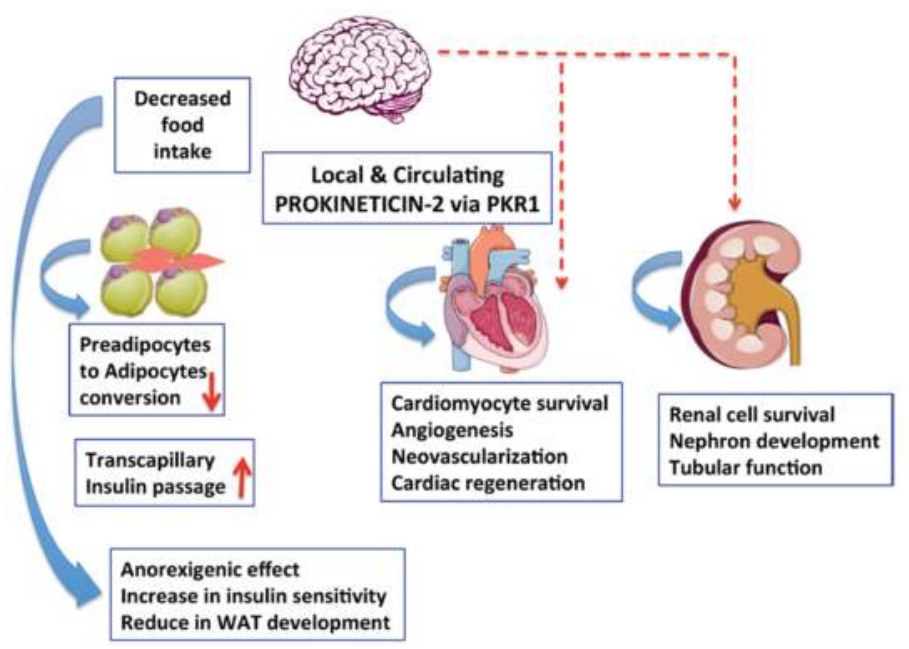

Figure 1. Prokineticin-2/PKR1 signaling may act as a new connector between development of obesity, diabetes and cardiovascular diseases. Prokineticin-2/PKR1 signaling in central nervous system (CNS) regulates food intake. Prokineticin-2 released from adipocytes controls preadipocyte conversion to adipocyte via PKR1 signaling. Prokineticin-2/PKR1 signaling promotes survival of cardiomyocytes and angiogenesis and involved in neovascularization by activating cardiac progenitor cells. Prokineticin-2/PKR1 signaling contributes to heart and kidney development as well as kidney function. Whether this signaling involves heart and kidney regulation through CNS remains to be studied.

\subsection{Prokineticin in insulin resistance}

The endothelium is essential for insulin transcapillary delivery to the skeletal muscle interstitium. This process is the rate-limiting step in insulin-stimulated glucose uptake. [24] The impairment of insulin delivery process contributes to insulin resistance [25]. On the other hand, insulin resistance leads to endothelial dysfunction [26]. Thus, the vascular endothelium is a potential therapeutic target for the prevention of insulin resistance and related complications [27].

Endothelium-specific PKR1-knockout mice (PKR1 $1^{\mathrm{ec}-\mathrm{-}}$ ) display impaired capillary formation and low transcapillary insulin uptake [23]. Impaired insulin delivery and signaling in endothelial cells (ECs) has been observed in cases of insulin resistance with type 2 diabetes and obesity. Endothelial cells overexpressing PKR1 promotes insulin transendothelial uptake [9] and angiogenesis [28]. PKR1 $1^{\text {ec- }}$ mice display lipodystrophy due to poor capillary formation in the AT. Lipodystrophies, involving a loss of WAT, cause hyperphagia and peripheral insulin resistance [29].

As a summary, prokineticin regulates appetite (effects in central nervous system (CNS)) and suppresses adipocyte expansion (direct effect on adipocyte tissue), promotes normal fat stor- 
age (endothelial-dependent effect) and increases insulin sensitivity. Therapeutic strategies targeting PKR1 could be important to treat obesity and obesity-associated insulin resistance.

\subsection{Prokineticin in cardiovascular regulation}

Obesity is both an independent risk factor and a risk marker for the development of asymptomatic and symptomatic coronary artery disease, heart failure and atrial fibrillation [2]. The relationship between obesity and cardiovascular diseases may be associated with hemodynamic and anatomic cardiovascular changes related to excess body mass [30]. However, the relationship can also be mediated by obesity-related metabolic, inflammatory and neurohormonal changes.

Altered expression of prokineticins and their receptors has been implicated in the development of a number of pathological cardiac conditions, including heart failure [31]. Prokineticins and their receptors have been identified as an important cardiovascular-signaling system especially cardiac cell commitment and cell-to-cell communications [32].

PKR1-mediated signaling contributes to cardiomyocyte survival and adult heart repair. PKR1 activates Akt in cardiomyocyte to protect these cells against hypoxia-mediated apoptosis [33]. Transgenic (TG) mice-overexpressing PKR1 in the cardiomyocytes (TG-PKR1) had an increased number of epicardial-derived progenitor cells (EPDCs), with an increase of capillary density and coronary arterioles. [32] The cardiac-PKR1 signaling up-regulates its own ligand prokineticin-2 to stimulate the EPDC differentiation into endothelial and smooth muscle cells to promote neovasculogenesis [32]. However, cardiomyocyte-PKR1 is essential for cardiomyocyte survival and contractility. PKR1 ${ }^{\text {null }}$ mice displayed cardiomyocyte-contractile defects and apoptosis partially due to lack of PKR1 signaling in cardiomyocytes. [34]

In endothelial cells (ECs), PKR1 activates Akt and MAPK to promote proliferation, migration and angiogenesis. In agreement with the in vitro findings, the specific loss of PKR1 from mouse ECs resulted in defective angiogenesis, leading to necrosis/apoptosis in the surrounding tissues in several organs, including the heart and kidneys [23].

There was significantly less capillary formation in adult PKR1 $1^{\mathrm{ec}-\mathrm{f}}$ hearts. The posterior walls of PKR1 $1^{\text {ec-l- }}$ hearts were thinner, which was due to the loss of capillary formation and a high level of apoptosis [23]. The remaining viable heart muscle is subject to greater biomechanical stress, triggering hypertrophy [23]. Shortening fractions (indicators of left ventricular contractility) were progressively reduced in mutant mice. PKR1 $1^{\text {ec-l- }}$ hearts displayed EC deregulation, capillary refraction, apoptosis, fibrosis and ectopic lipid deposition, abnormal insulin signaling in hearts resulting in impaired diastolic function.

The ECs of hearts exhibited severely decreased FICT-insulin uptake, indicating defective transcapillary transport of insulin in the vascular wall of these mice. Isolated ECs from the mutant cardiac and renal tissues exhibited very little insulin uptake, confirming that the loss of PKR1 from EC decreased insulin transport [23]. Overexpressing PKR1 in these ECs promoted fluorescein isothiocyanate (FITC)-insulin passage. Indeed, the primary defect linking insulin resistance and endothelial dysfunction is believed to be nitric oxide deficiency of endothelial origin [35]. In agreement, insulin uptake and insulin-mediated eNOS activation 
were impaired in all mutant ECs. Similarly, altered eNOS activation and low insulin action have recently been demonstrated in the endothelium of patients with diabetes mellitus [36]. Thus, impaired insulin delivery to ECs may lead to defective NOS and eNOS activation in PKR1 ${ }^{\text {ec- }-}$ aortas, consequently impairing endothelium-dependent relaxation. These data highlight the role of PKR1 as a positive regulator of insulin uptake [37].

PKR1 signaling also contributes to heart development. In developing heart, PKR1 regulates epicardial-mesenchymal transition (EMT) to form epicardial-derived progenitor cell (EPDC) [38]. Genetic ablation of PKR1 in epicardium leads to ventricular hypoplasia and septal defects during embryogenesis. Impaired vasculogenesis in these mice is due to impaired EPDC proliferation as well as a defective EPDC differentiation into endothelial and smooth muscle cell type. PKR1 in EPDCS activates Akt signaling, changes cell morphology, actin cytoskeleton remodeling and EMT gene expression profile. Epicardial-PKR1 contributes to cardiomyocyte, proliferation and rhythmicity in a paracrine pathway.

\subsection{Prokineticin in renal development and function}

Global PKR1-knockout mice have peripheral obesity accompanied by a diabetes-like syndrome at the late ages (36 weeks old) [7], mainly due to endothelial dysfunction and impaired adipose tissue functions [37]. These mice also exhibited cardiomegaly, severe interstitial fibrosis and cardiac dysfunction under the stress conditions. These mice also displayed impaired renal tubular dilation, reduced glomerular capillaries, urinary phosphate excretion and proteinuria [34].

Similarly, endothelial-specific PKR1-knockout mice (PKR1 $1^{\mathrm{ec}-\mathrm{-}}$ ) also displayed dilatation of Bowman's spaces in most glomeruli, a compact glomerulus, fibrosis and enlarged tubular structures with a swollen necrotic nucleus, abnormal mitochondria and aberrant organization of podocytes. Abnormal tubular function with higher levels of absolute renal phosphate (Pi) excretion in the PKR1 $1^{\mathrm{ec}-\mathrm{f}}$ mice is due to lower levels of sodium-calcium and sodium phosphate exchanger. The morphological changes in the PKR $1^{\mathrm{ec}-{ }_{-}}$kidneys were associated with higher levels of apoptosis and impaired insulin signaling and lipid accumulation. Mutant mice displayed high levels of creatinine clearance and proteinuria. [34] Endothelial dysfunction resulted from loss of PKR1 signaling partially underlies the pathological features of heart and kidney.

PKR1 signaling in kidney is essential for nephron development during embryogenesis [38]. Recently, it has been shown that mutant mice with targeted PKR1 gene disruptions in nephron progenitors exhibited partial embryonic and postnatal lethality due to hypoplastic kidneys with premature glomeruli and necrotic nephrons. Kidney developmental defects in these mice are manifested in the adult stage as renal atrophy with glomerular defects, nephropathy and uremia. Thus, PKR1 is necessary for renal mesenchymal-epithelial transition (MET) that is involved in the formation of renal progenitors, regulating glomerulogenesis toward forming nephrons during kidney development. Indeed, PKR1 through NFATc3 modifies MET processing to the development of nephron. 


\section{Conclusion}

PKR1 signaling has various beneficial effects, e.g., central regulation of appetite, the suppression of adipocyte mass and insulin-sensitizing effects on skeletal muscle and other tissues, cardiac regenerative effects and regulation of kidney function. This has attracted considerable interest in the possible use of this receptor as a target for treatments combating obesity, diabetes and cardiovascular diseases. Intracardiac PKR1 gene transfer improved survival rate and heart functions after myocardial infarction [33]. Since PKR2 has been found to contribute to vascular leakage and hypertrophic cardiomyopathy [39], several laboratories are focused on the discovery of PKR1 agonist. Recently, PKR1 non-peptide agonist has been identified [40]. PKR1 agonist prevents cardiac lesion formation and improved cardiac function after myocardial infarction in mice, promoting proliferation of cardiac progenitor cells and neovasculogenesis. PKR1 agonist in treatment strategies of metabolic disease remains to be studied.

How prokineticin-2 contributes to the AT remodeling [41], how it modulates the interaction between the adipocytes, macrophages and endothelial cells to regulate AT expansion [42] remains also to be determined. Circulating prokineticin levels in obese, diabetic and heart failure patients remain to be explored.

\section{Acknowledgements}

I wish to thank people involved in the studies described here, including Kyoji Urayama, Célia Guilini, Gulen Turkeri, Monia Boulberdaa, Mojdeh Dormishian, Rehana Qureshi, Himanshu Arora and Adeline Gasser. The publication was supported in part by grants from Fondation pour la Recherche Médicale (Equipe Labellisée), Centre National de la Recherche Scientifique and Université de Strasbourg. This work has also been published within the LABEX ANR10-LABX- 0034_Medalis and received a financial support from the French government managed by Agence Nationale de la Recherche (ANR) under "Programme d'investissement d'avenir."

\section{Author details}

Canan Nebigil

Address all correspondence to: nebigil@unistra.fr

CNRS-University of Strasbourg, (UMR 7242), Illkirch, France 


\section{References}

[1] Haslam DW and James WP. Obesity. Lancet. 2005;366:1197-209.

[2] Mandviwala T, Khalid U and Deswal A. Obesity and cardiovascular disease: a risk factor or a risk marker? Curr Atheroscler Rep. 2016;18:21.

[3] Valassi E, Scacchi M and Cavagnini F. Neuroendocrine control of food intake. Nutr Metab Cardiovasc Dis. 2008;18:158-68.

[4] Mikulaskova B, Maletinska L, Zicha J and Kunes J. The role of food intake regulating peptides in cardiovascular regulation. Mol Cell Endocrinol. 2016;436:78-92.

[5] Monnier J and Samson M. Cytokine properties of prokineticins. FEBS J. 2008;275:401421.

[6] Kaser A, Winklmayr M, Lepperdinger G and Kreil G. The AVIT protein family. Secreted cysteine-rich vertebrate proteins with diverse functions. EMBO Rep. 2003;4:469-73.

[7] Szatkowski C, Vallet J, Dormishian M, Messaddeq N, Valet P, Boulberdaa M, Metzger D, Chambon P and Nebigil CG. Prokineticin receptor 1 as a novel suppressor of preadipocyte proliferation and differentiation to control obesity. PLoS One. 2013;8:e81175.

[8] Li M, Bullock CM, Knauer DJ, Ehlert FJ and Zhou QY. Identification of two prokineticin cDNAs: recombinant proteins potently contract gastrointestinal smooth muscle. $\mathrm{Mol}$ Pharmacol. 2001;59:692-8.

[9] LeCouter J and Ferrara N. EG-VEGF and the concept of tissue-specific angiogenic growth factors. Semin Cell Dev Biol. 2002;13:3-8.

[10] Wechselberger C, Puglisi R, Engel E, Lepperdinger G, Boitani C and Kreil G. The mammalian homologues of frog Bv8 are mainly expressed in spermatocytes. FEBS Lett. 1999;462:177-81.

[11] Nebigil CG. Prokineticin receptors in cardiovascular function: foe or friend? Trends Cardiovasc Med. 2009;19:55-60.

[12] Ross MG and Desai M. Developmental programming of appetite/satiety. Ann Nutr Metab. 2014;64(Suppl 1):36-44.

[13] Coll AP, Farooqi IS, Challis BG, Yeo GS and O'Rahilly S. Proopiomelanocortin and energy balance: insights from human and murine genetics. J Clin Endocrinol Metab. 2004;89:2557-62.

[14] Sobrino Crespo C, Perianes Cachero A, Puebla Jimenez L, Barrios V and Arilla Ferreiro E. Peptides and food intake. Front Endocrinol (Lausanne). 2014;5:58.

[15] Gardiner JV, Bataveljic A, Patel NA, Bewick GA, Roy D, Campbell D, Greenwood HC, Murphy KG, Hameed S, Jethwa PH, Ebling FJ, Vickers SP, Cheetham S, Ghatei MA, 
Bloom SR and Dhillo WS. Prokineticin 2 is a hypothalamic neuropeptide that potently inhibits food intake. Diabetes. 2010;59:397-406.

[16] Chaly AL, Srisai D, Gardner EE and Sebag JA. The melanocortin receptor accessory protein 2 promotes food intake through inhibition of the prokineticin receptor-1. Elife. 2016;5. p ii: e12397.

[17] Beale K, Gardiner JV, Bewick GA, Hostomska K, Patel NA, Hussain SS, Jayasena CN, Ebling FJ, Jethwa PH, Prosser HM, Lattanzi R, Negri L, Ghatei MA, Bloom SR and Dhillo WS. Peripheral administration of prokineticin 2 potently reduces food intake and body weight in mice via the brainstem. Br J Pharmacol. 2013;168:403-10.

[18] Iwasa T, Matsuzaki T, Munkhzaya M, Tungalagsuvd A, Kawami T, Murakami M, Yamasaki M, Kato T, Kuwahara A, Yasui T and Irahara M. Changes in the responsiveness of hypothalamic prokineticin 2 mRNA expression to food deprivation in developing female rats. Int J Dev Neurosci. 2014;34:76-8.

[19] Sarfati J, Guiochon-Mantel A, Rondard P, Arnulf I, Garcia-Pinero A, Wolczynski S, Brailly-Tabard S, Bidet M, Ramos-Arroyo M, Mathieu M, Lienhardt-Roussie A, Morgan G, Turki Z, Bremont C, Lespinasse J, Du Boullay H, Chabbert-Buffet N, Jacquemont $S$, Reach G, De Talence N, Tonella P, Conrad B, Despert F, Delobel B, Brue T, Bouvattier C, Cabrol S, Pugeat M, Murat A, Bouchard P, Hardelin JP, Dode C and Young J. A comparative phenotypic study of Kallmann syndrome patients carrying monoallelic and biallelic mutations in the prokineticin 2 or prokineticin receptor 2 genes. J Clin Endocrinol Metab. 2010;95:659-69.

[20] Hill JO, Wyatt HR and Peters JC. Energy balance and obesity. Circulation. 2012;126:12632.

[21] Ma X, Lee P, Chisholm DJ and James DE. Control of adipocyte differentiation in different fat depots; implications for pathophysiology or therapy. Front Endocrinol (Lausanne). 2015;6:1.

[22] Lafontan M. Adipose tissue and adipocyte dysregulation. Diabetes Metab. 2014;40:1628.

[23] Dormishian M, Turkeri G, Urayama K, Nguyen TL, Boulberdaa M, Messaddeq N, Renault G, Henrion D and Nebigil CG. Prokineticin receptor-1 is a new regulator of endothelial insulin uptake and capillary formation to control insulin sensitivity and cardiovascular and kidney functions. J Am Heart Assoc. 2013;2:e000411.

[24] Kubota T, Kubota N, Kumagai H, Yamaguchi S, Kozono H, Takahashi T, Inoue M, Itoh S, Takamoto I, Sasako T, Kumagai K, Kawai T, Hashimoto S, Kobayashi T, Sato M, Tokuyama K, Nishimura S, Tsunoda M, Ide T, Murakami K, Yamazaki T, Ezaki O, Kawamura K, Masuda H, Moroi M, Sugi K, Oike Y, Shimokawa H, Yanagihara N, Tsutsui M, Terauchi Y, Tobe K, Nagai R, Kamata K, Inoue K, Kodama T, Ueki K and Kadowaki T. Impaired insulin signaling in endothelial cells reduces insulin-induced glucose uptake by skeletal muscle. Cell Metab. 2011;13:294-307. 
[25] Genders AJ, Frison V, Abramson SR and Barrett EJ. Endothelial cells actively concentrate insulin during its transendothelial transport. Microcirculation. 2013;20:434-9.

[26] Prieto D, Contreras C and Sanchez A. Endothelial dysfunction, obesity and insulin resistance. Curr Vasc Pharmacol. 2014;12:412-26.

[27] Cao Y. Angiogenesis as a therapeutic target for obesity and metabolic diseases. Chem Immunol Allergy. 2014;99:170-9.

[28] Guilini C, Urayama K, Turkeri G, Dedeoglu DB, Kurose H, Messaddeq N and Nebigil CG. Divergent roles of prokineticin receptors in the endothelial cells: angiogenesis and fenestration. Am J Physiol Heart Circ Physiol. 2010;298:H844-52.

[29] Guo T, Bond ND, Jou W, Gavrilova O, Portas J and McPherron AC. Myostatin inhibition prevents diabetes and hyperphagia in a mouse model of lipodystrophy. Diabetes. 2012;61:2414-23.

[30] von Bibra H, Paulus W and St John Sutton M. Cardiometabolic syndrome and increased risk of heart failure. Curr Heart Fail Rep. 2016;13:4 ;1-11

[31] Urban JD, Clarke WP, von Zastrow M, Nichols DE, Kobilka B, Weinstein H, Javitch JA, Roth BL, Christopoulos A, Sexton PM, Miller KJ, Spedding M and Mailman RB. Functional selectivity and classical concepts of quantitative pharmacology. J Pharmacol Exp Ther. 2007;320:1-13.

[32] Urayama K, Guilini C, Turkeri G, Takir S, Kurose H, Messaddeq N, Dierich A and Nebigil CG. Prokineticin receptor-1 induces neovascularization and epicardial-derived progenitor cell differentiation. Arterioscler Thromb Vasc Biol. 2008;28:841-9.

[33] Urayama K, Guilini C, Messaddeq N, Hu K, Steenman M, Kurose H, Ert G and Nebigil CG. The prokineticin receptor-1 (GPR73) promotes cardiomyocyte survival and angiogenesis. FASEB J. 2007;21:2980-93.

[34] Boulberdaa M, Turkeri G, Urayama K, Dormishian M, Szatkowski C, Zimmer L, Messaddeq N, Laugel V, Dolle P and Nebigil CG. Genetic inactivation of prokineticin receptor-1 leads to heart and kidney disorders. Arterioscler Thromb Vasc Biol. 2011;31:842-50.

[35] Duncan ER, Crossey PA, Walker S, Anilkumar N, Poston L, Douglas G, Ezzat VA, Wheatcroft SB, Shah AM and Kearney MT. Effect of endothelium-specific insulin resistance on endothelial function in vivo. Diabetes. 2008;57:3307-14.

[36] Tabit CE, Shenouda SM, Holbrook M, Fetterman JL, Kiani S, Frame AA, Kluge MA, Held A, Dohadwala MM, Gokce N, Farb MG, Rosenzweig J, Ruderman N, Vita JA and Hamburg NM. Protein kinase C-beta contributes to impaired endothelial insulin signaling in humans with diabetes mellitus. Circulation. 2013;127:86-95.

[37] Von Hunolstein JJ and Nebigil CG. Can prokineticin prevent obesity and insulin resistance? Curr Opin Endocrinol Diabetes Obes. 2015;22:367-73. 
[38] Arora H, Boulberdaa M, Qureshi R, Bitirim V, Gasser A, Messaddeq N, Dolle P and Nebigil CG. Prokineticin receptor-1 signaling promotes epicardial to mesenchymal transition during heart development. Sci Rep. 2016;6:25541.

[39] Urayama K, Dedeoglu DB, Guilini C, Frantz S, Ertl G, Messaddeq N and Nebigil CG. Transgenic myocardial overexpression of prokineticin receptor-2 (GPR73b) induces hypertrophy and capillary vessel leakage. Cardiovasc Res. 2009;81:28-37.

[40] Gasser A, Brogi S, Urayama K, Nishi T, Kurose H, Tafi A, Ribeiro N, Desaubry L and Nebigil CG. Discovery and cardioprotective effects of the first non-Peptide agonists of the G protein-coupled prokineticin receptor-1. PLoS One. 2015;10:e121027.

[41] Sun K, Kusminski CM and Scherer PE. Adipose tissue remodeling and obesity. J Clin Invest. 2011;121:2094-101.

[42] Molgat AS, Gagnon A and Sorisky A. Macrophage-induced preadipocyte survival depends on signaling through Akt, ERK1/2 and reactive oxygen species. Exp Cell Res. 2011;317:521-30. 
